\title{
EFFECT OF TEMPERATURE ON THE BEHAVIOUR OF ASPHALTIC CONCRETE MIXTURES UNDER REPEATED \\ LOADS \\ By
}

\author{
Dr.Eng. Saad A. El-Hamrawy \\ Faculty of Eng. Menoufia Uni. \\ Shebin El-kom
}

\section{-ABSTRACT}

In the recent years an important trend has been established towards the use of heavier highway and aircraft wheel loading. The high axle loads lead to excessive permanent deformation in asphalt pavements, especially at high temeratures in hot regions.

The main objective of this research is to study the effect of test temperatures on the creep behavior of asphalt concrete mixtures. Dynamic creep test was used for this purpose. Creep strain, mix stiffness modules and rate of deformation were obtained as a function of axial applied stress and/or test temperature.

It is concluded that the creep strain, rate of deformation and mix stiffness modules depends upon the bitumen stiffness, and influenced proportionally by variation of test temperature.

Key Words: Permanent deformation, rutting, creep test, load repetitions, Pavement, Asphalt mixtures.

\section{-INTRODUCTION}

A major concern today in many countries is excessive permanent deformation (rutting) in heavy duty asphalt-concrete pavements resulting from frequent repetitions of heavy axle loads.

Viscoelastic behaviour of asphalt concrete mixes can be investigated in the laboratory through determining the stiffness, strength, resilience and deformation properties of compacted specimens at various conditions of temperature, load levels and loading rates.

Manuscript received from Dr: Dr. Saad El-Hamrawy at: 10/5/1998, accepted at: 30/ 6/1998,

Engineering research bulletin, Vol. 21, No. 2, 1998, Menoufiya University, Faculty of Engineering, Shebin El- Kom, Egypt, ISSN. 1110-1180. 
Temperature has been found to have a significant effect on permanent deformation. Rutting determined from test - track measurements showed that rut depth increased by a factor of 250 to 350 with a temperature increase from 20 to $60^{\circ} \mathrm{C}$ [1]. Permanent deformation can be controlled by optimization of the asphalt mixture and the pavement condition and by optimization of the design of heavy duty trucks. Also, it was found that wheel load and tire inflation pressure have a strong influence on rutting [2].

The creep test (unconfined or confined) has been used to measure mixture characteristics for a variety of predictive methods. Among its users have been researchers at the SHELL laboratory in Amsterdam. They have conducted extensive studies using the unconfined creep test as a basis for predicting rut depth in asphalt pavements $[3,4,5]$.

The main objective of this research is to study the effect of test temperature on the creep behaviour of asphaltic concrete mixes. The repeated load test was used for this purpose.

\section{-BACKGROUND:}

Asphalt pavements experience service conditions in the field which include simultaneous different temperatures, different load levels as well as loading rates and different loading frequencies. These service conditions make the asphalt pavement mixtures undergo cyclic changes in the stiffness, strength, resilience and deformation. The cyclic changes may lead to fracture or permanent deformations.

The compression creep tests can be used for investigating the deformation properties, and can be classified into three types, STATIC-, DYNAMIC- and IMPELS creep tests. A detailed description of the compression creep tests for asphaltic concrete mixtures has been given by VAN DE LOO [6]. .

Static creep test is the most widespread one for determining material properties for predictive analysis because of its simplicity and the fact that many laboratories have the necessary equipment and expertise [7].

A variety of loading systems has been used to measure mixture response in repeated loading, ranging from simple mechanical systems to more complex elector-hydraulic systems [8,9]. More sophisticated systems generally include a testing chamber that permits careful control of temperature as well as the application of repeated load confining pressure coordinated with the vertical repeated load. Such equipment may have the following capabilities: 
1.Applying repeated axial and lateral stress pulses ranging from 0.01 to 1.0 seconds;

2.Applying the axial stress in tension or compression;

3.Incorporating rest periods between stress pulses, ranging from zero to several seconds;

4.Controlling temperature within a tolerance of $0.1^{\circ} \mathrm{C}$.

Repeated load tests appear to be more sensitive to mixture variables than static creep tests. For example, on the basis of shell creep tests, an increase in the asphalt content of a particular mixture from 4.5 to $5.5 \%$ should not have a significant effect on the rut depth, while the results of repeated load tests on the same mixture indicated that such an increase in asphalt content could increase the rut depth by $16 \%$ [10].

\section{-CREEP BEHAVIOUR OF ASPHALTIC CONCRETE MIXTURES:}

Asphalt pavements experience some amount of instantaneous elastic strain when they are loaded. If the applied stress is more than the elastic limit, an additional plastic strain is developed. If the load is removed after a short time, only the elastic strain will be recovered, while the plastic strain will be remained.

If the load is applied for a significantly long period of time, viscoelastic strain (creep strain) will be developed. If the load is removed at any time, only part of the creep strain will be recovered, while the remaining creep will be a permanent strain. Fig. (1) shows a schematic diagram of the time (Load repetitions) strain relationship for a sample of asphalt mixes loaded below the elastic limit. As shown from the figure, the creep strain can be divided into three stages. In the first stage, the rate of creep strain is maximum at the beginning and decreases with time. In the second stage, the rate of strain remains constant. Finally, at the third stage, the rate of creep strain increases significantly until creep reputure occurs.

\section{-MATERIALS AND TESTING PROGRAM}

All experiments described in this research were performed on cylindrical Marshall test specimens of asphaltic concrete mixes which meet the German specifications ZTV Asphalt stB 94. The laboratory compacted Marshall specimens were prepared from one type of aggregate (granite from Pliesskowitz), has $11.0 \mathrm{~mm}$ maximum size . The aggregate gradation is presented in Fig. 2 . The experimental testing program is illustrated in Tab.1. The properties of the asphalt 
cement and the asphalt concrete mixtures are presented in Tab. 2 and Tab. 3 respectively.

The dynamic creep test was the principal experiment utilized to evaluate the influence of test temperature on the behaviour of asphaltic concrete mixes. The dynamic creep tests were performed on the laboratory compacted asphaltic concrete at different five temperatures $40,45,50,55$ and $60^{\circ} \mathrm{C}$. Three experiments were performed on the test specimens under identical conditions. For all experiments, a different axial stress levels were utilized to evaluate the viscoelastic response of the material. The axial stress levels were $0.4,0.5$, and 0.6 $\mathrm{N} / \mathrm{mm} 2$. The dynamic creep test was performed for most specimens to $150,000 \mathrm{load}$ repetitions (4 hours and $10 \mathrm{~min}$.). Some specimens, which tested at low temperature were stayed until 500,000 load repetitions.

The pre-pressure (pre-stress) and the test frequency were constant for all tests and equal $0.01 \mathrm{~N} / \mathrm{mm} 2$ and $10 \mathrm{~Hz}$ respectively. All tests were performed under isothermal conditions with a maximum temperature variation of $\pm 0.5{ }^{\circ} \mathrm{C}$. During the repeated creep test, the axial load F (axial stress) was constant, while the creep strain (s) increased until failure ( Fig.3). The axial deformation of the asphaltic concrete specimens was measured as a function of the time or load repetitions. The relationship between the number of load repetitions and vertical deformation or vertical strain can be automatically obtained by using a computer program DGM as shown in Fig.1.

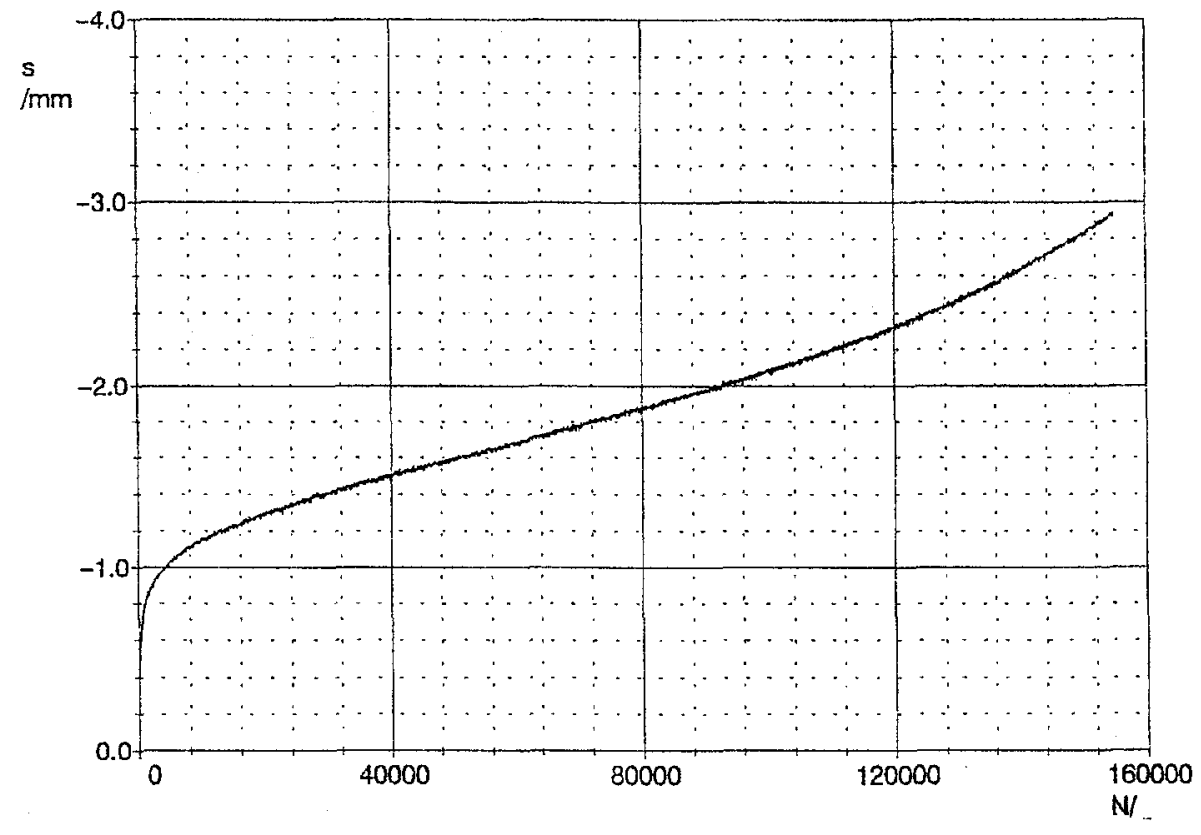

Fig.1:Relationship between Load Repititions (N) and Vertical Deformation (s). 


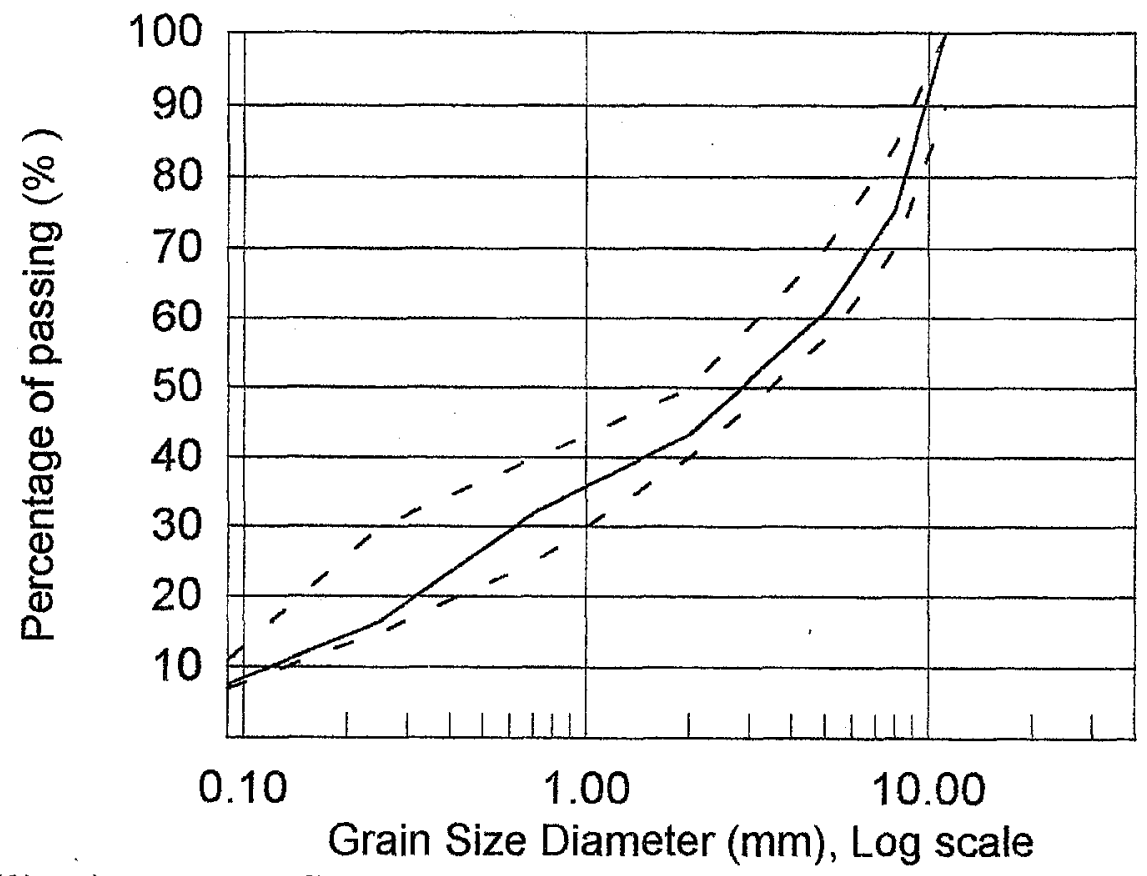

Fig. (2) : Aggregate Gradation of Asphalt Mixture

Tab.1: Experimental Testing Program

\begin{tabular}{|l|c|c|}
\hline Type of Asphalt & $\mathrm{AC}, \%$ & Test Temp. ${ }^{\circ} \mathrm{C}$ \\
\hline AC 60-70 (B65 -German spec.) & 5.6 & 50 \\
& 5.9 & $40,45,50,55,60$ \\
& 6.2 & 50 \\
\hline AC 85 (B80 -German spec.) & 5.9 & 50 \\
\hline
\end{tabular}

Tab. 2: Asphalt cement characteristic

\begin{tabular}{|lr|c|c|}
\hline Property & \multicolumn{1}{|c|}{ B65 } & B80 \\
\hline Penetration at $25^{\circ} \mathrm{C}$ r $\quad(1 / 10 \mathrm{~mm})$ & 61 & 78 \\
Softening point, Ring and Ball $\quad\left({ }^{\circ} \mathrm{C}\right)$ & 53 & 69 \\
Ductility at $25^{\circ} \mathrm{Cr}$ & $(\mathrm{cm})$ & 115 & 141 \\
Specific gravity & $(\mathrm{gm} / \mathrm{cm} 3)$ & 1.03 & 1.02 \\
\hline
\end{tabular}

Tab.3 : Characteristic of asphalt concrete mixture

\begin{tabular}{|lc|l|l|l|}
\hline Property & AC-wt-\% & 5.6 & 5.9 & 6.2 \\
\hline Marshall stability & $(\mathrm{kN})$ & 12.0 & 12.3 & 11.50 \\
Marshall Flow & $(\mathrm{mm})$ & 3.5 & 3.8 & 4.1 \\
Bulk density & (g/cm3) & 2.39 & 2.40 & 2.42 \\
Voids content & (vol.-\%) & 4.6 & 3.7 & 2.5 \\
Asphalt content & $(\mathrm{M}-\%)$ & 5.6 & 5.9 & 6.2 \\
Asphalt content & $($ vol.-\%) & 13.0 & 13.8 & 14.6 \\
\multicolumn{2}{l|}{ Voids filled with asphalt \% } & 73.80 & 78.80 & 85.40 \\
\hline
\end{tabular}




\section{-DESCRIPTION OF THE TEST METHOD :}

An asphalt concrete specimen with flat and parallel ends is placed between two hardened steel platens, one of which is fixed and the other movable. The specimens ends must be lubricated to prevent the platens from laterally constraining the specimen and to provide a uniform stress distribution. A constant load is placed on the movable platen, and the deformation of the specimen is measured as a function of time. The temperature is kept constant during the total test time. The test machine for creep test (static, dynamic and impels) is shown in Fig. 4. Strain, measured as a function of the loading time $(t)$ at a fixed test temperature $(T)$, is the usual test output.

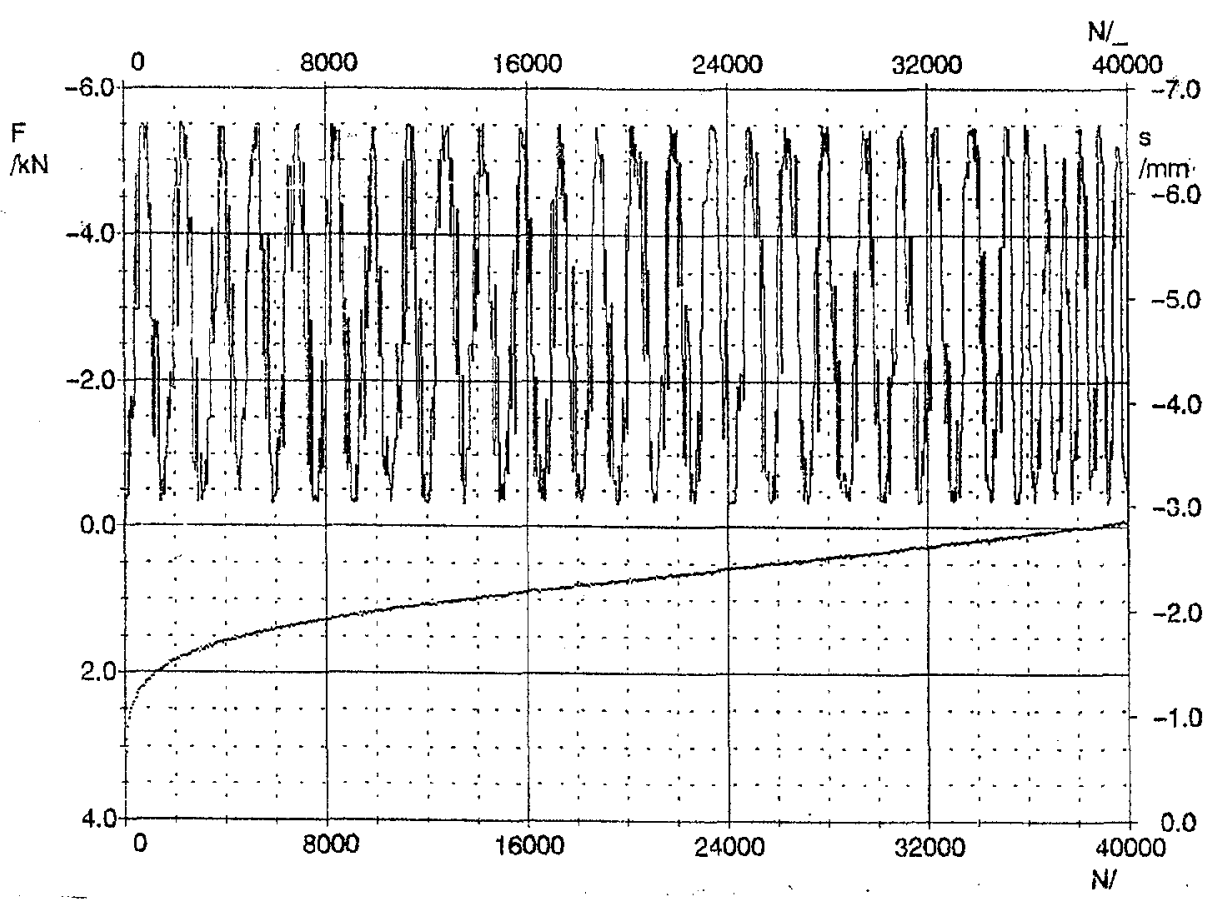

Fig.3:Relationship between Load Repititions (N), Axial Load (F) and Vertical Deformation (s) 


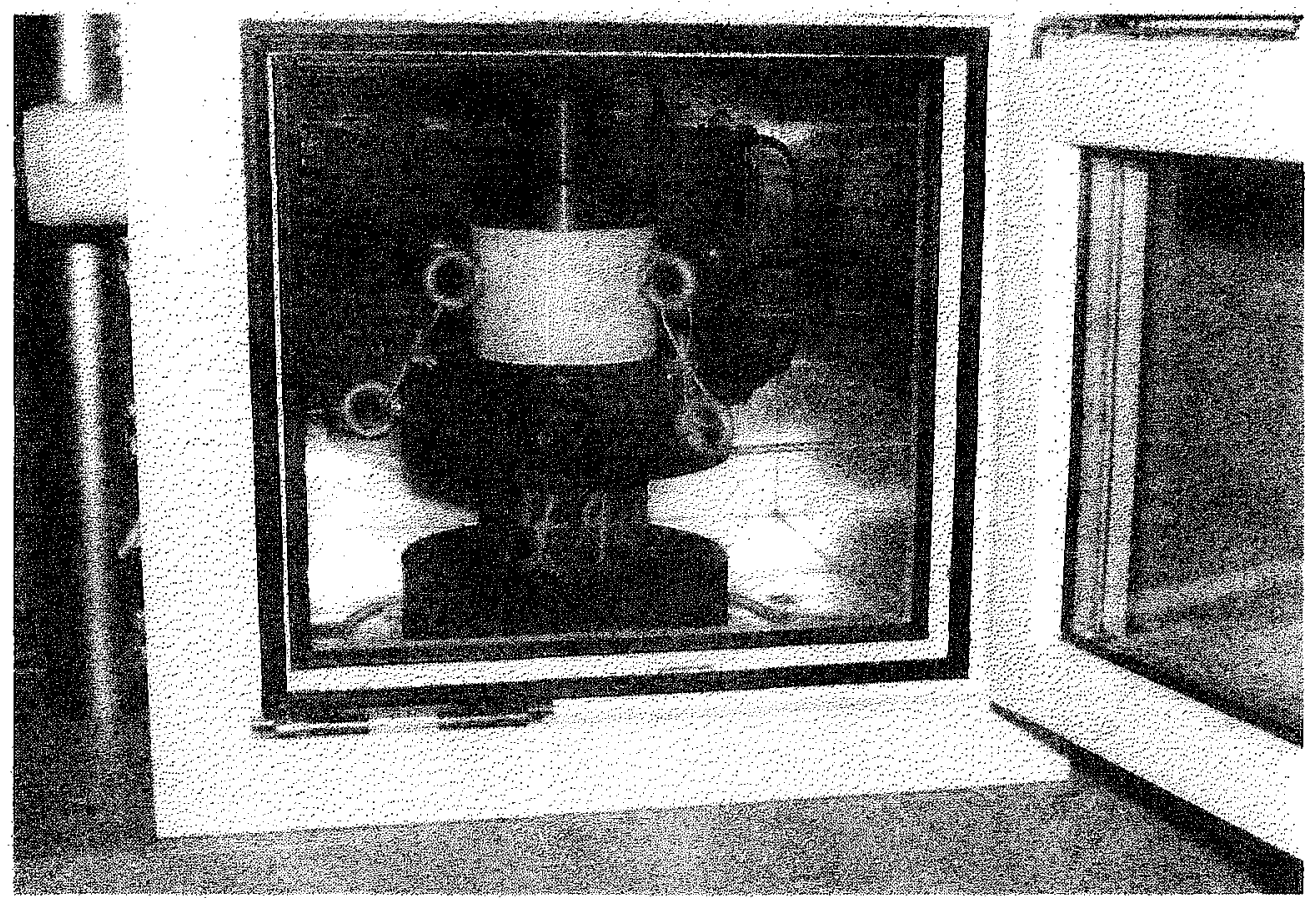

Fig.d: Creep Test Apparatus ( TU - Dresden)

\section{ANALYSIS OF TEST RESULTS:}

To analyze the effect of test temperature on the behaviour of asphaltic concrete mixtures under repeated loads, some mix properties were determined as follows:

1) Creep strain (c) : Creep strain can be obtained directly as a test result or calculated from the following equation:

$$
\varepsilon=\Delta h / h \times 1000 \quad[0 / 00]
$$

2) Rate of deformation : It is the slope of time -deformation curve in linear region (Fig.2).

3) Mix stiffness modules: $S=(\sigma 0, N f) / \& f \quad[\mathrm{~N} / \mathrm{mm} 2]$ where :

$\Delta \mathrm{h}=$ deformation at time $\mathrm{t}(\mathrm{mm})$;

$\mathrm{h}=$ thickness of specimen $(\mathrm{mm})$;

бo=applied stress $\quad(\mathrm{N} / \mathrm{mm} 2)$;

$\mathrm{Nf}=$ number of load repetitions at failure (-);

$\varepsilon f=$ strain at failure $(\mathrm{o} / \mathrm{oo})$. 
Creep strain, rate of deformation and mix stiffness modules are calculated in linear region at 20,000 load repitetions (LR) .

\section{Creep Strain Related to Load Repetitions:}

Fig. 5 shows the effect of load repetitions on creep strain at various test temperatures. It should be noted that the three curves of 40,45 and $50{ }^{\circ} \mathrm{C}$ are parallel, while at 55 and $60^{\circ} \mathrm{C}$ test temperature, the increase in creep strain is more significant and the failure is faster. This mean that in hot regions, the increase of pavement temperature more than $50{ }^{\circ} \mathrm{C}$ lead to more creep strain and consequently the permanent deformation or rut depth increases ( the creep failure is faster).

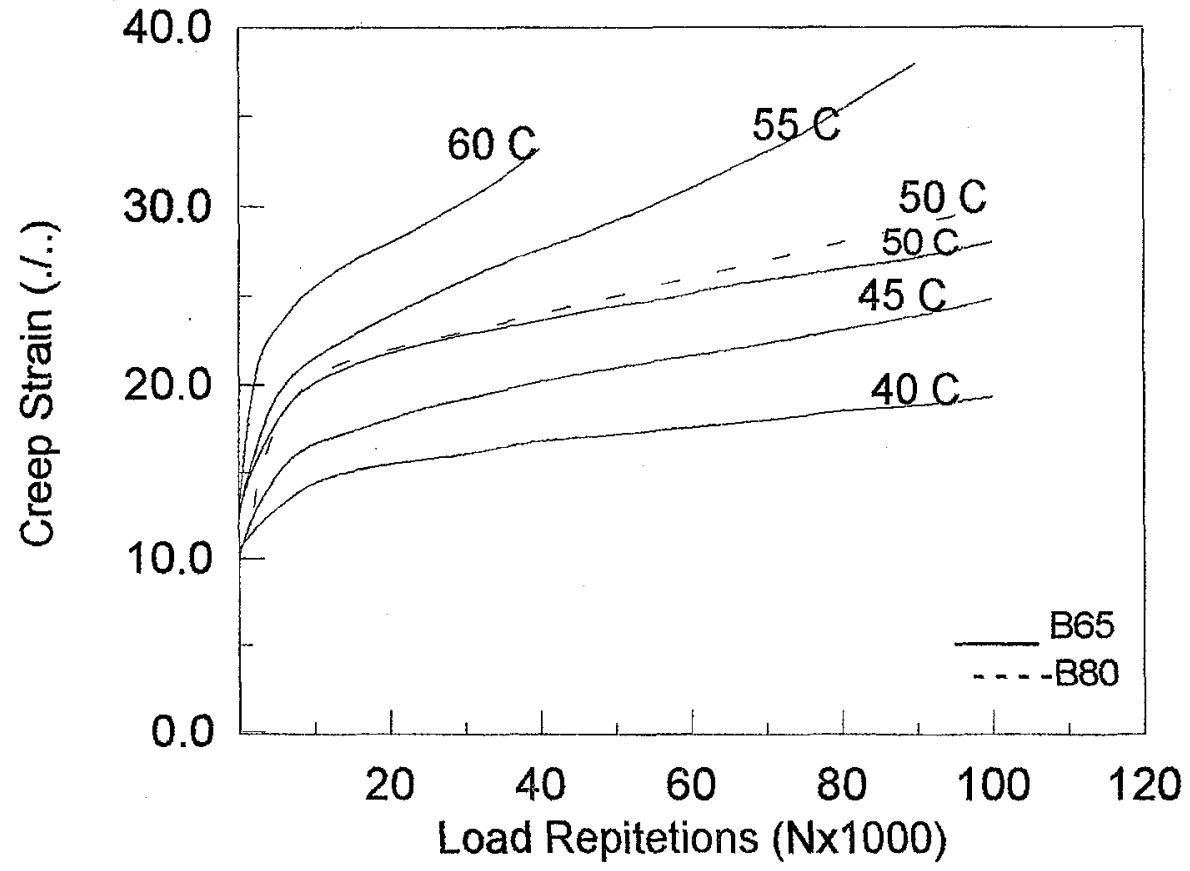

Fig. (5) : Effect of Load Repetitions on Creep Strain as A function of Test Temperature.

Moreover, at the same test temperature, the creep strain increases as the viscosity of asphalt decreases (Values of creep strain for mixes with $\mathrm{B} 80$ is higher than their values for mixes with $\mathrm{B} 65$ ).

\section{Creep Strain Related to Test Temperature:}

The relationship between the applied axial stress and creep strain as a function of test temperature at 20,000 load repetitions is shown in Fig.6 . It should be recognized that for the same mix, the creep strain significantly increases as the test temperature increases. For example, at $40^{\circ} \mathrm{C}$ test temperature, the creep strain various between 14 to $17 . /$. , while at $60^{\circ} \mathrm{C}$ test temperature, the creep strain increases from 20 to 27 \%.. according to the axial applied stress. This may be return to the 
asphalt binder which coates the aggregate particles is more liquefy at high test temperatures (bitumen viscosity decreases) and lead to loss of stability and gain in flow values as well as creep strain . Moreover, at the same test temperature, the creep strain increases as the axial applied stress increases. Also, effect of increasing axial stresses depends upon test temperature. For example, increasing the axial stresses from 0.4 to $0.6 \mathrm{~N} / \mathrm{mm} 2$, increases the creep strain by $21 \%$ at $40{ }^{\circ} \mathrm{C}$ and by $35 \%$ at $60^{\circ} \mathrm{C}$. Increasing both temperature from 40 to 60 ${ }^{\circ} \mathrm{C}$ and axial

stress from 0.4 to $0.6 \mathrm{~N} / \mathrm{mm} 2$ lead to increase in creep strain by more than $100 \%$.

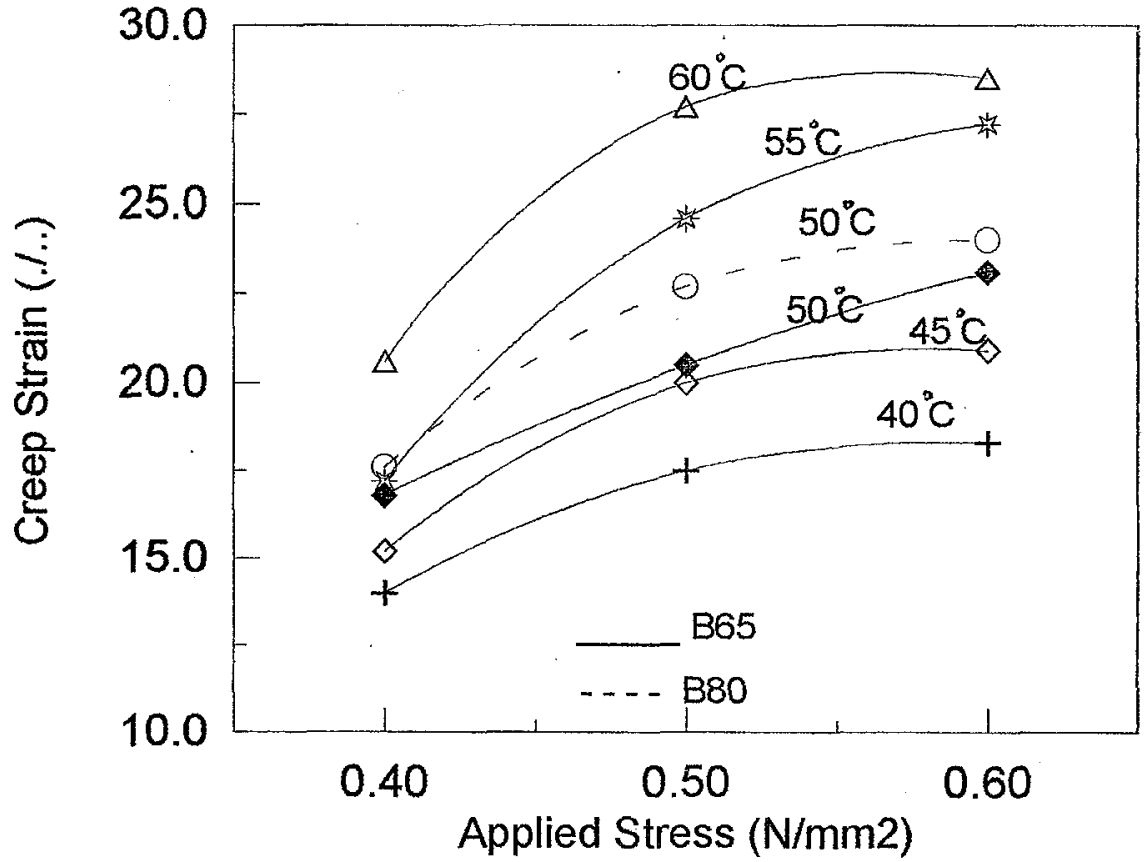

Fig. (6) : Relationship between Creep Strain and Applied Stress as $A$ function of Test Temperature.

\section{Rate of Deformation Related to Test Temperature:}

Fig. 7 shows the relationship between the axial applied stress and rate of deformation as a function of test temperature at 20,000 load repetitions. It should be noted that the rate of deformation increases as the test temperature and/or applied stress increases. By increasing the axial stress from 0.4 to $0.6 \mathrm{~N} / \mathrm{mm} 2$ at $40^{\circ} \mathrm{C}$ test temperature, rate of deformation increases from 3 to $18 \%$, while at $60^{\circ} \mathrm{C}$ test temperature, the increase of rate of deformation lies between 21 to $27 \%$ according to applied stress. This mean that, larger wheel loads and larger tire inflation pressures increase the rate of deformation of asphalt concrete mixes at all temperatures. 


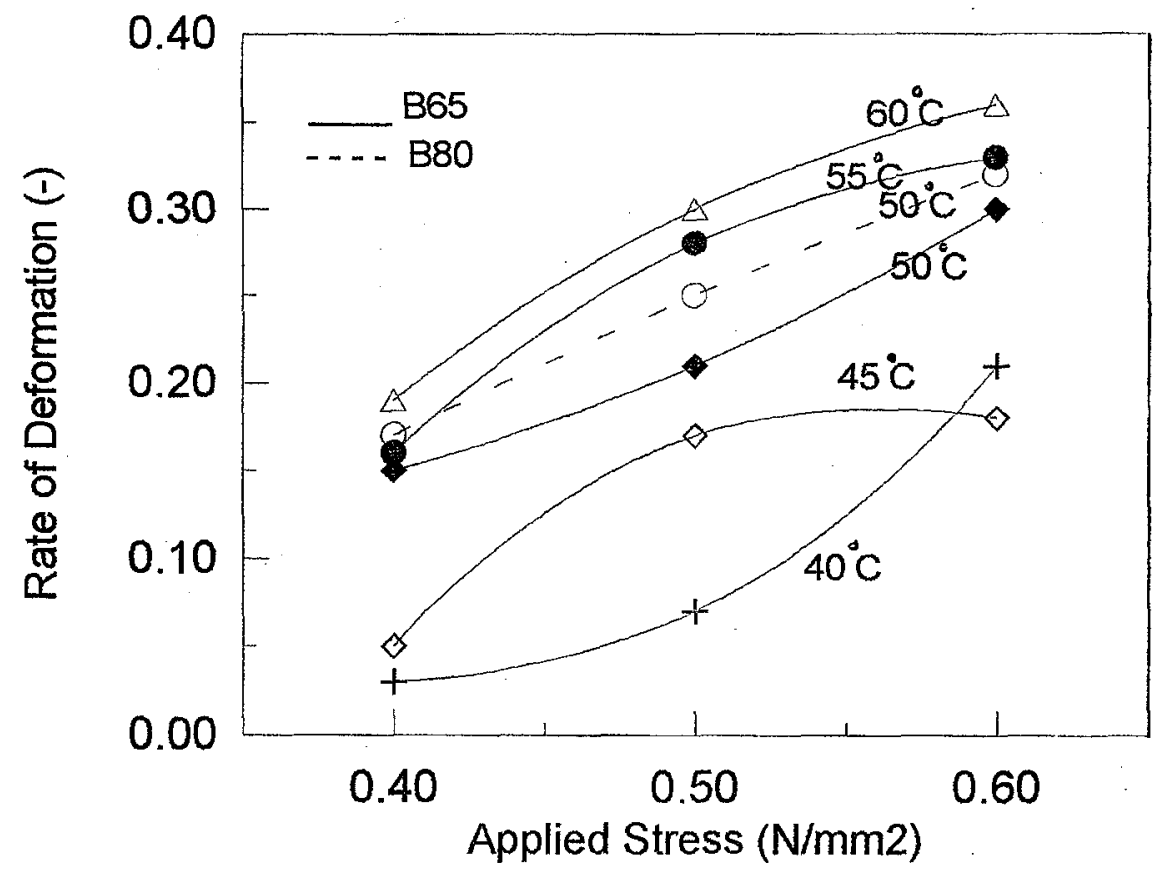

Fig.(7) : Relationship between Rate of Deformation and Axial Stress as A function of Test Temperature.

Fig. 8 shows a relation between mix stiffness modules and rate of Deformation . From this regression analysis, it is noted that the rate of deformation decreases as the mix stiffness modules increases. This mean that harder asphalts should be used in bot regions to reduce the rate of permenant deformation. The relation between mix stiffness modules $(\mathrm{X})$ and rate of deformation $(\mathrm{Y})$ is as follows:

$$
\log (Y)=-0.29 \log (X)+5.32
$$

\section{Mix Stiffness Modules related to Test Temperature:}

Fig.9 gives a relationship between mix stiffness modules and axial stress as a function of test temperature. It is noted that increasing test temperature lead to a significant decrease in the stiffness modules of asphalt mixtures. According to equation (1), the mix stiffness modules is a function of axial applied stress at failure, creep strain at failure and number of load repetitions at failure. At a constant applied stress, as the test temperature increases the number of load repetitions at failure decreases and the creep strain at failure increases and consequently the stiffness modules decreases. Also, at a constant test temperature, by increasing the applied stress the number of load repetitions at failure decreases and the creep strain at failure increases and the final result is decrease in the stiffness modules. 


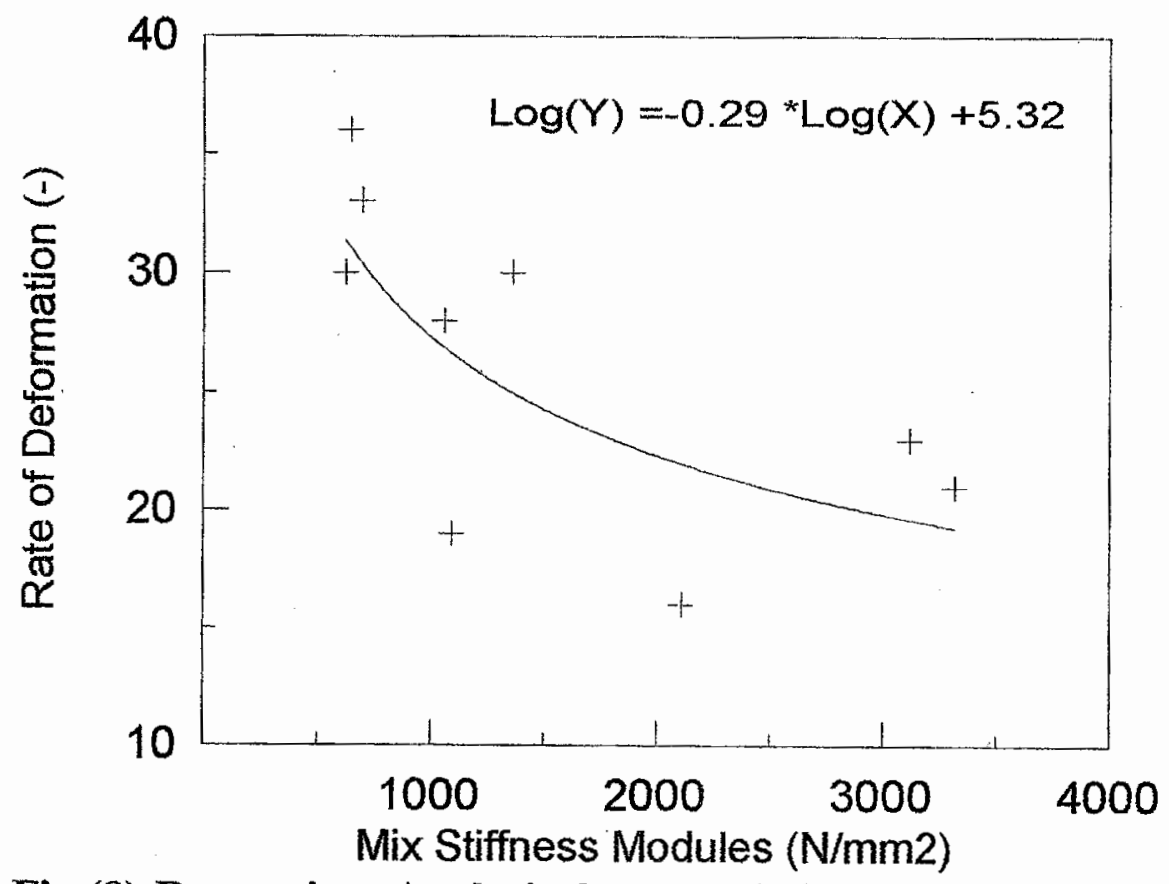

Fig.(8):Regression Analysis between Mix Stiffness Modules and Rate of Deformation.

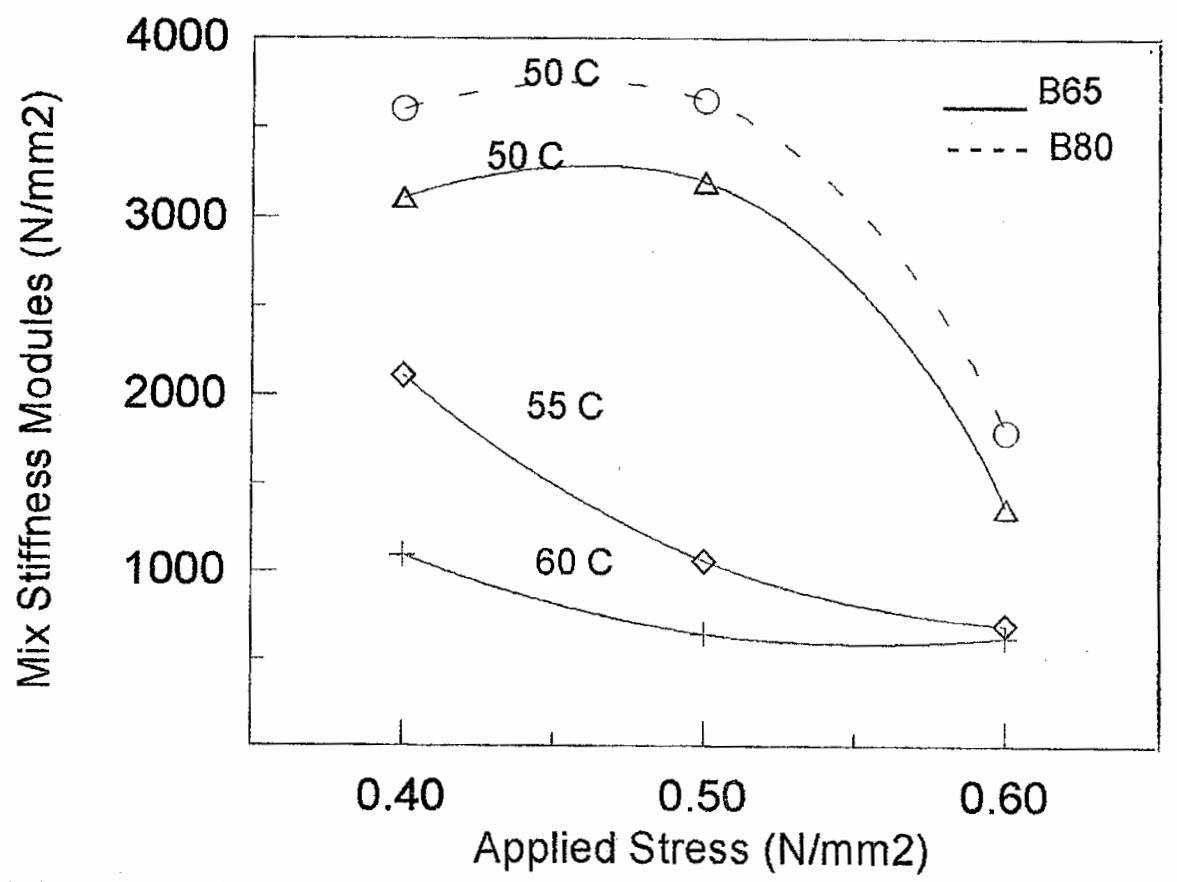

Fig. (9) : Relationship between Mix Stiffness Modules and Axial Stress as A function of Test Temperature. 
Moreover,mix stiffness modules is almost directly proportional to the stiffness modules of bitumen ( Fig.10). The stiffness modules of bitumen can be predicted using the VAN DER POEL nomograph [11]. This modules depends upon loading time, temperature and penetration index of binder.

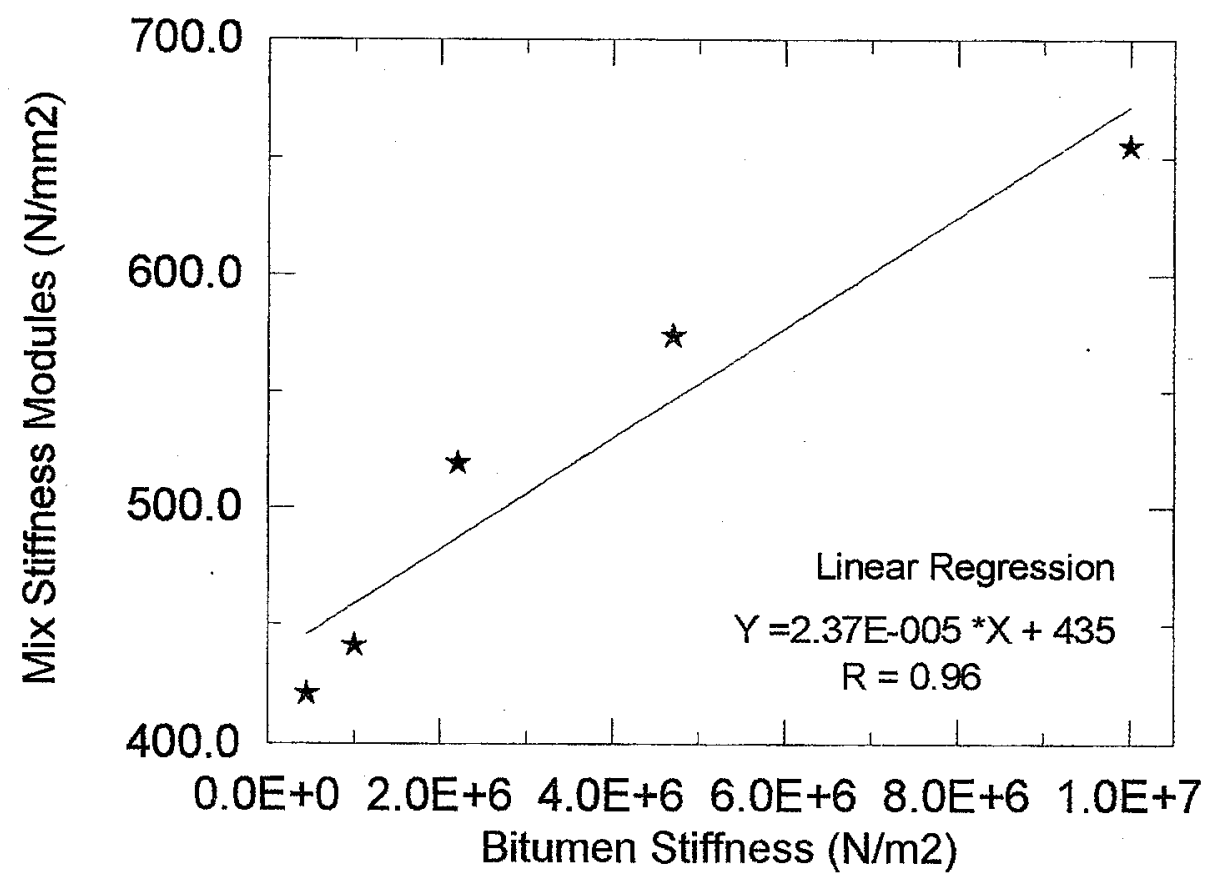

Fig.(10) : Regression Analysis between Mix Stiffness Modules and Bitumen Stiffness. 


\section{CONCLUSION}

1. Larger viscosity asphalts make the mixture less stiff and, therefore, more susceptible to permenant deformation, harder (more viscous) asphalts should be used in thicker pavements in hotter climates. The increase of pavement temperature more than $50^{\circ} \mathrm{C}$ lead to more creep strain and consequently the permanent deformation or rut depth increases ( the creep failure is faster).

2. The binder content influences the mixtures ability to resist permanent deformation. Larger binder contents increase creep strain and subsequently rutting potential.

3. For the same mix, creep strain increases as the test temperature as well as axial applied stress increases .Increasing both temperature from 40 to $60^{\circ} \mathrm{C}$ and axial stress from 0.4 to $0.6 \mathrm{~N} / \mathrm{mm} 2$ lead to increase in creep strain by more than $100 \%$.

4. larger wheel loads and larger tire inflation pressures increase the rate of deformation of asphalt concrete mixes at all temperatures. Rate of deformation decreases as the mix stiffness modules increases. So that, harder asphalts should be used in hot regions to reduce the rate of permenant deformation. The relation between mix stiffness modules $(\mathrm{X})$ and rate of deformation $(\mathrm{Y})$ is as follows:

$$
\log (Y)=-0.29 \log (X)+5.32
$$

5. At a constant applied stress, as the test temperature increases the number of load repetitions at failure decreases and the creep strain at failure increases and consequently the stiffness modules decreases. Also, at a constant test temperature, by increasing the applied stress the number of load repetitions at failure decreases and the creep strain at failure increases and consquently the stiffness modules decreases. Moreover, mix stiffness modules $\left(y^{\prime}\right)$ is almost directly proportional to the stiffness modules of bitumen ( $\left.\mathrm{X}^{\prime}\right)$ as follows:

$$
Y^{\prime}=2.37 E-005 * X+435
$$

\section{REFERENCES}

/1/Herbst,G., Piber,H. : The Deformation Modulus : A possibility to define the behaviour of asphalt., Proceeding of the fifth international RILEM symposium - Mechanical Tests for Bituminous Materials -, Lyon 1997. 
/2/Eisenmann,J., and Hilmer: Influence of Wheel Load and Inflation Pressure on the Rutting Effect at Asphalt-Pavements-Experiments and Theoritical Investigations, Proceedings, Sixth International Conference on the Structural Design of Asphalt Pavements, Vol.I, Ann Arbor (1987), pp. 209-219 .

13/ Hills,J.F.: The Creep of Asphalt Concrete Mixes, Journal of The Institute of Petroleum, Nov.1973.

14/ Van de Loo,P.J.:Practical Approach to the Prediction of Rutting in Asphalt Pavements, the Shell Method, Transportation Research Record, 616, P.15-21.

15/ Shell Pavement Design Manual. Shell International Petroleum Company Limited, London, England, 1978.

16/ Van de Loo,P.J.(1978). The Creep Test: A key Tool in Asphalt Mix Evaluation and in Prediction of Rutting, Proceedings, The Association of Asphalt Paving Technologists, Vol.47,522-557.

/7/Kim.O.K.a.o.:Study on Mix Design Criteria for Controlling the Effect of Increased Tire Pressure on Asphalt Pavement., Transportation Research Record 1171, 1991, pp.149-159.

/8/Piber,H.:Asphaltprüfungen - Ringversuch an Druckprüfmaschinen, Bitumen 4/1997, pp. 173 - 177.

19/Paulmann, a.o.: Arbeitsanleitung für die Ansprache des Verformungs-verhaltens von Walzasphalten bei Wärme mit Hilfe des einaxialen Druckschwell- versuches., Institute für Strassen und Eisenbahnwesen, Uni.Karlsruhe, 1994.

/10/Barksdale, R.D., and J.H.Miller II.(1977) Development of Equipment and Techniques for Evaluating Fatigue and Rutting Characteristics of Asphalt Concrete Mixes, School of Civil Engineering, Georgia Institute of Technology, SCEGIT-77-149.

/11/Van der Poel,C.: A general System Describing the Visco - Elastic Properties of Bitumens and its Relation to Routine Test Data., Journal of Applied Chemistry Vol.4 (1954) P.221 


\title{
تأثتير الحرارة على الثلطنات الأسفلتية تحت الأحمسال

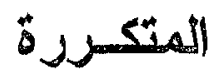

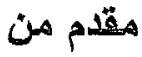

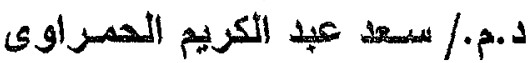

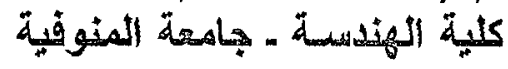

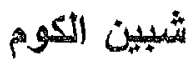

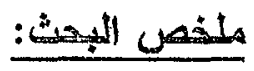

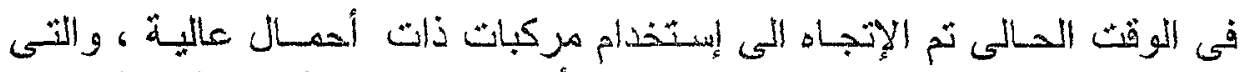

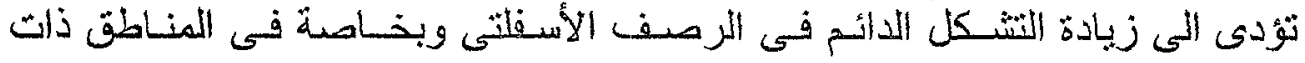

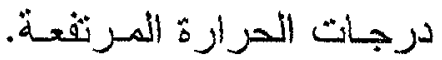

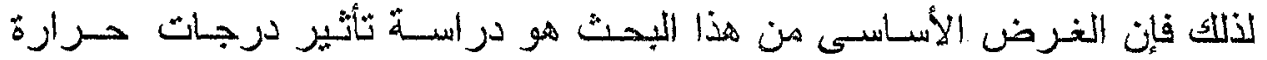

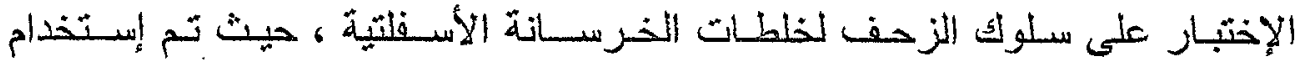

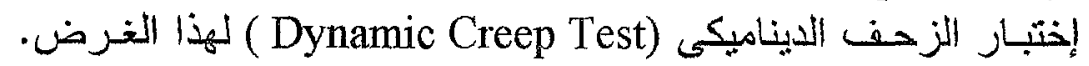

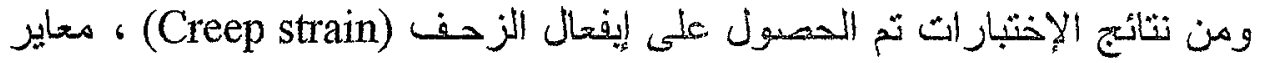

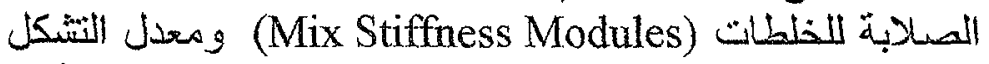

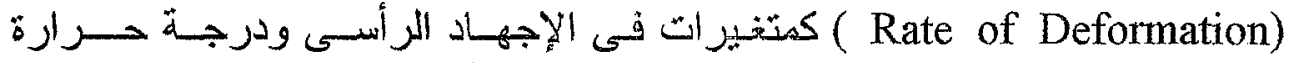

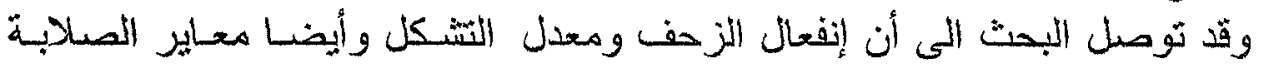

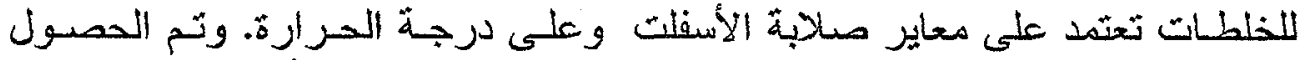
على معادلة خطية تزبط بين كلا من معاير الصلابة للخطات درات والأسفلت. 